Niğde Ömer Halisdemir Üniversitesi Mühendislik Bilimleri Dergisi
Niğde Ömer Halisdemir University Journal of Engineering Sciences
ISSN: 2564-6605
Araştırma / Research

\title{
Google Earth Engine ile arazi kullanımı haritalarının üretimi
}

\author{
Producing land use maps with Google Earth Engine
}

\section{Majid Aghlmand 1 (D), Kaan Kalkan 2,* (D), Mehmet İnanç Onur 1 (D), Gürkan Öztürk 3 (iD), Ecem Ulutak 4 (iD)}

\author{
${ }^{1}$ Eskişehir Teknik Üniversitesi, İnşaat Mühendisliği Bölümü, Eskişehir, Türkiye \\ ${ }^{2}$ TÜBITAK Uzay Teknolojileri Araştırma Enstitüsü, Ankara, Türkiye \\ ${ }^{3}$ Eskişehir Teknik Üniversitesi, Endüstri Mühendisliği Bölümü, Eskişehir, Türkiye \\ ${ }^{4}$ Eskişehir Teknik Üniversitesi, Yer ve Uzay Bilimleri Enstitüsü, Eskişehir, Türkiye
}

\section{Özet}

Sürekli gelisen sehirler, nüfus artısı ve iklimsel kosullar gibi ekosistem de meydana gelen olumsuz etkenler ile arazi kullanımı değişime uğramaktadır. Uzaktan algllama uyduları tarafindan üretilen veriler. yeryüzü araștırmalarda önemli bir rol oynamaktadır. Arazi örtüsü/kullanımı haritaları bu veriler kullanılarak hazırlanmaktadır. Arazi örtüsü haritalarl, su ve biyokimyasal döngüler, enerji değisimleri veya biyolojik çeşitlilik değişiklikleri gibi çevresel süreçleri daha iyi anlamamıza yardımcı olur. Bu çalıșma, Google Earth Engine bulut platformunda arazi kullanım haritalarının üretilebilirliğini test etmek amacıyla gerçekleştirilmiştir. Bu amaçla 01/01/2019 ve 01/01/2020 tarihleri arasinda Landsat 8. Sentinel 1 ve Sentinel 2 uydulart tarafindan çekilen tüm görüntüler kullanılmıştır. Daha sonra 5 farklı endeks; NDVI (Normalleştirilmiş fark bitki örtüsü endeksi), EVI(Gelişmiş Bitki Örtüsü Endeksi), NDWI (Normalleștirilmiş fark su endeksi), NDBI (Normalleştirilmiş fark oluşturma indeksi) ve UI (Kentsel indeks) hesaplanmis ve 19 farkl veri kombinasyonu dikkate alınmıstır. Daha sonra bu kombinasyonlarin her biri Destek Vektör Makineleri yöntemi(LibSVM) kullanılarak 5 sinıfa (Sehir alanı-yollar, su, ormanlıkkoruluk, tarım dıș araziler ve tarım arazileri) ayrılmıștır. Her sınıflandırma için genel doğruluk ve Kappa Katsayısı hesaplanmış ve sonuclar karsilastırllmistır. En iyi sinıflandırma, Landsat8, Sentinel-2. Sentinel-1 (VV), Landsat 8'den NDVI, Sentinel-2'den NDVI, NDBI, UI ve NDWI veri kombinasyonuna aittir. Bu kombinasyonda toplam doğruluk 96.62 ve kappa katsayıs 95.76 olmuştur.

Anahtar kelimeler: Arazi kullanım haritaları, Eskişehir, Google Earth Engine, Kontrollü sınıflandırma, Uzaktan algılama

\section{Giriş}

Küresel iklim değişikliğinin sonuçları gün geçtikçe kendisini hissettirmektedir [1]. Gelişen şehirler ve büyüyen insan nüfusu ile birlikte arazi kullanımlarının değerlendirilmesi ve analizi oldukça önemlidir. Küresel iklim değişikliğinin neden ve sonuçları ile alınması gereken önlemler belirlenmelidir [2]. Uzaktan algilama ve uydu görüntüleri sayesinde arazi kullanımın gözlemi ve analizini yapabilmek mümkündür. Son birkaç yıl içerisinde ortaya çıkan orta ve yüksek çözünürlüklü uydu görüntüleri ile uzaktan algılama yöntemleri ve uygulamalarına yenileri eklenmiştir [3, 4].

Uzaktan algılama görüntülerinden üretilen arazi örtüsü haritaları, arazi kaynakları yönetimi, kentsel planlama, hassas tarım ve çevre koruma gibi birçok alanda önemli bir rol oynamaktadır [5-8]. Arazi örtüsü haritaları, su ve biyokimyasal döngüleri, enerji değişimleri veya biyolojik
Abstract

Land use are changing due to negative factors occurring in the ecosystem such as continuously developing cities, population growth, and climatic conditions. Data produced by remote sensing satellites play an essential role in ground-based research. Land cover maps are prepared using this data. Land cover maps help us better understand environmental processes such as water and biogeochemical cycles, energy changes, or biodiversity changes. This study was carried out to test the producibility of land use maps on the Google Earth Engine cloud platform. All images acquired between 01/01/2019 and 01/01/2020 from Landsat 8, Sentinel 1, and Sentinel 2 were used in this study. Then 5 different indices NDVI, NDWI, NDBI, Ui, and EVI were calculated, and 19 different combinations of data were considered. Then, for each of these combinations, classification was performed by the LibSVM method in 5 classes: Urban Roads, Water, Forest-Grove, Non-agricultural Lands, and Agricultural Lands. Overal Accuracy and Kappa Coefficient were calculated for each classification, and results were compared. The best classification with Overall Accuracy 96.62 and Kappa Coefficient 95.76 belongs to the data combination of Landsat 8, Sentinel-1(VV), Sentinel-2, NDVI, NDBI, UI and NDWI from Sentinel-2 and NDVI from Landsat 8.

Keywords: Land use maps, Eskişehir, Google Earth Engine, Supervised classification, Remote sensing

çeşitlilik değişiklikleri gibi çevresel süreçleri daha iyi anlamamıza yardımcı olur [9].

Arazi örtüsü, temel iklim değişkeni olarak kabul edilmiştir ve ayrıca uzaktan algılama temel biyo-çeşitlilik değişkeni olarak önerilmiştir [10, 11]. Arazi örtüsünün, tematik ve yüksek çözünürlükte görüntülenebilir olması dünya yüzeyinin kolay bir şekilde izlenmesini ve karşılaştırma yapılmasını sağlamaktadır [12].

$\mathrm{Bu}$ sayede yeni nesil arazi kullanım analizleri ve haritaları ortaya çıkmıştır $[13,14]$. Arazi kullanım haritalaması birkaç basamaktan oluşmaktadır. $\mathrm{Bu}$ basamaklar; verilerin seçilmesi, verilerin işlemesi ve sınıflandırma işlemleridir. Eğer seçilen alan, ulusal veya bölgesel olarak seçilmiş ve oldukça büyük ise, verinin işlenmesinde sorunlar yaşanabilmektedir. Bir yıla ait büyük bir alanda pek çok uydu görüntüsünden yararlanılması gerektiği için bulutluluk oranı, verilerin büyüklüğü ve işlenmesi aşamalarında zorluklar yaşanabilmektedir.

\footnotetext{
* Sorumlu yazar / Corresponding author, e-posta / e-mail: kalkaan@ gmail.com (K. Kalkan)

Geliş / Recieved: 16.09.2020 Kabul / Accepted: 02.01.2021 Yayımlanma / Published: 15.01.2021

doi: 10.28948 /ngumuh.795977
} 
Ücretsiz olarak uydu görüntüsü elde etmek gün geçtikçe daha kolay hale gelmektedir. Copernicus program [15] buna bir iyi örnektir. Sentinel-1 [16] ve Sentinel-2 [17] European Space Agency (ESA) Copernicus'a ait olan, iklim değişimi, güvenlik ve acil durum müdahalesi gibi durumlarda kullanılan ve veri sürekliliğini sağlamak için kullanılan uydulardır Sentinel-1 uydusunda bulunan radar sensörü bulutlardan etkilenmemektedir. Sentinel-1, Sentinel-2 ve Landsat 8 [18] uydu görüntülerine Google Earth Engine (GEE) [19] üzerinden kolay bir şekilde erişim sağlanabilmektedir. GEE uygulaması görüntüleri işlemede yerel saklama yerine bulut ortamında veriyi işlemeyi sağlamaktadır. $\mathrm{Bu}$ sayede bilgisayar özelliklerine bakılmaksızın istenilen sayıda görüntü sayısı çok daha hızlı ve kolay bir şekilde yapılabilmektedir. Bu tip platformlar sayesinde araştırmacılar büyük alanlarda büyük boyutta verileri analiz ederek sonuç elde edebilmektedir GEE büyük ölçekli verilerde hem donanımsal olarak güçlü bilgisayarlarla olan ihtiyacı azalmakta hem de kısa bir zaman diliminde analizi gerçekleştirerek kullanıcıların tasarruf yapmalarını sağlamaktadır [20]. GEE uygulamasında yer alan veri setleri oldukça zengindir. Farklı uydulara ait pek çok tarih aralığında bulunan uydu görüntülerini kullanabilmek mümkündür [21]. GEE kullanırken piksel seçimlerinde mean, median, min, max v.b. farklı yöntemler bulunmaktadır. Aynı zamanda GEE aracı ile bulut oranlarının az olduğu bölgeleri seçerken kod panelinden yararlanılarak bulutluluk oranının istenildiği şekilde seçilebilmesi mümkündür [22].

Farklı arazi örtüsü sınıfları göz önüne alınarak, uzaktan algılama alanında kullanılan birçok farklı yöntem değerlendirilerek, uzaktan algılanmış görüntülerde spektral ve spektral-uzamsal özelliklerin kullanımı farklı çalışmalarda araştırılmıştır [23-25].

NDVI(Normalleştirilmiş fark bitki örtüsü endeksi) ve EVI(Gelişmiş Bitki Örtüsü Endeksi) gibi indekslerin arazi kullanımı haritalamasında kullanımı bu haritaların üretilmesinde verimliliği arttırmaktadır. $\mathrm{Bu}$ indeksler sayesinde farklı alanların biyokütleleri hakkında bilgi edilebilmektedir. Ayrıca, yaprak alan indeksi, biyokütle, kapalılık, fotosentez aktivitesi ve üretkenliği gibi analizler gerçekleştirilebilir [26, 27]. NDWI(Normalleştirilmiş fark su endeksi) su alanlarının bulunmasında ve bitkilerdeki su içeriğinin tespitinde verimli bir şekilde kullanılan bir indekstir [28]. Uydu görüntülerinde, yapılaşmış alanlar ile toprak alanlarını ayırt etmek genellikle zordur, bu arazi kullanımı türlerinin ayırılmasında doğruluğu arttıran
NDBI(Normalleştirilmiş fark oluşturma indeks) ve Ui(Kentsel indeks) gibi indeksler kullanılmaktadır [29, 30].

$\mathrm{Bu}$ çalışma, Landsat 8, Sentinel-1 ve Sentinel-2 uydularından elde edilen verileri kullanarak Eskişehir ili arazi kullanımı haritalarının üretiminde en iyi doğruluğu elde etmek amacıyla yapılmıştır. Bu amaçla, 01/01/2019 ve 01/01/2020 döneminde bu üç uydudan çekilen tüm görüntüler işleme alınmıştır. Ayrıca, sınıflandırmada NDVI, EVI, NDWI, NDBI ve Ui indeksleri hesaplanmıştır. Sınıflandırmanın temel verisini Landsat 8 oluşturacak şekilde planlanarak, tüm katmanların çözünürlüğü 30 metreye yeniden örneklenmiştir. Ardından, GEE'de LIBSVM yöntemini seçerek sınıflandırma farklı kombinasyonlarda adım adım gerçekleştirilmiştir. Her sinıflandırma için Overal Accuracy ve Kappa Coefficient değerleri hesaplanmış ve sonuçlar karşılaştırılmıştır.

\section{Materyal ve metot}

\section{1 Çalışma alanı}

Çalışma alanı olarak Eskişehir ili seçilmiştir (Şekil 1). Eskişehir kuzeyinde Karadeniz, kuzeybatıda Marmara, batı ve güneybatıda Ege bölgesi ile komşu olmakla birlikte İç Anadolu Bölgesi'nin kuzeybatısında yer almaktadır. Eskişehir'in deniz yüksekliği ise 792 metredir. Eskişehir'in Seyitgazi, Sarıcakaya, Mihallıçık ilçelerinde farklı iklimler görülse de Eskişehir'in genel coğrafi karakteri İç Anadolu Bölgesine benzemektedir. Eskişehir'in alanı yaklaşık 13,653 $\mathrm{km}^{2}$ 'dir. Eskişehir'in kuzeyinde Bozdağ ve Sündiken dağları, güneyinde Emirdağ, doğuda Orta Asya vadisi ve batısında Türkmen dağları bulunmaktadır. Türkiye'nin tüm alanı ile Eskişehir oranlandığında Eskişehir ili Türkiye'nin $\% 1.8$ 'ini oluşturmaktadır [31]

\subsection{Google Earth Engine (GEE)}

GEE, bulut tabanlı coğrafi veri işleme platformdur ve tüm analizleri çok kısa bir sürede gerçekleştirmeyi sağlamaktadır. Google destekli platformda bulunan ve toplanan veriler herkesin erişimine açık olarak sunulmuştur. Ağaç, orman ve su alanları, arazi kullanımındaki değişiklikleri veya tarım alanlarının sağlığını değerlendirmek için GEE'yi kullanabilmek mümkündür. GEE, son 40 y1l içerisinde küresel ölçekli birçok veriyi sunmaktadır. Platform veri sunmakla kalmayıp aynı zamanda analiz yapmayı sağlayan oldukça güçlü araçlar içermektedir [32-35].
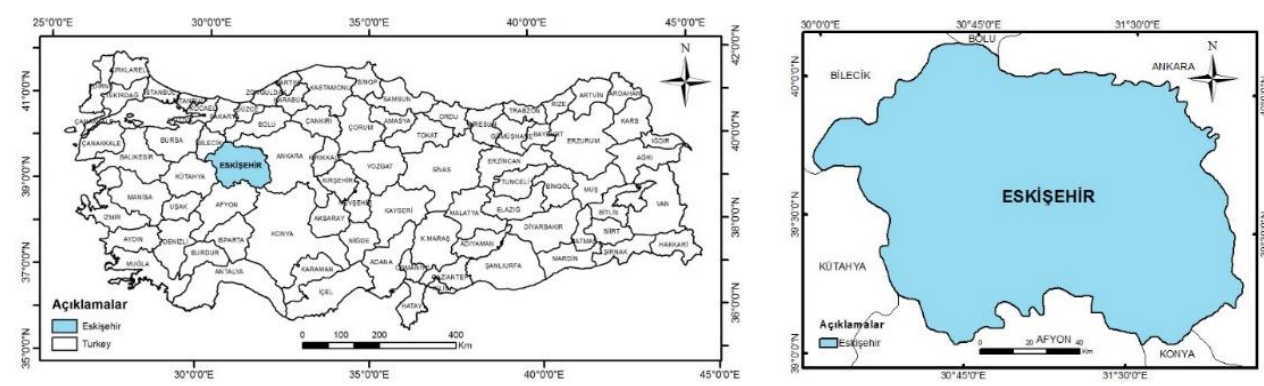

Şekil 1. Çalışma alanı 
Landsat 8, Sentinel-1 ve Sentinel-2 verileri GEE'de mevcuttur. Bu çalışmada Landsat 8, Sentinel-1 ve Sentinel2 verileri kullanılmıştır. GEE içerisindeki veriler, kullanıcıya hazır halde sunulmaktadır ve herhangi bir önişleme sürecinden geçirilmesi gerekmeyecek şekilde analizlerde kullanılabilir. Bu çalıșmada kullanılan Sentinel-1 SAR GRD görüntüleri, termal gürültü giderme, radyometrik kalibrasyon ve arazi düzeltmesi gibi ön-işleme süreçlerinden geçirilmiştir. Sentinel-2 görüntülerine ise Level-1C ve Level-2A formatında erişilebilmektedir. $\mathrm{Bu}$ çalışmada Level-2A verileri kullanılmıștır. Landsat 8 verileri 3 ayrı önişleme seviyesinde sunulmaktadır; yüzey yansıtımı (Surface Reflectance), atmosfer üstü yansitım (Top of Atmosphere) ve ham görüntüler. Bu çalıșmada atmosferik düzeltmesi yapılmış yüzey yansıtımı verileri kullanılmıştır [36].

Çalışmada, 5 farklı indeks hesaplanmıştır. NDVI, EVI, NDWI, NDBI ve UI her biri hakkında bilgiler aşağıda verilmiştir.

\subsection{Landsat 8}

GEE'de bulunan Landsat 8 verileri, LaSRC yönetime ile atmosferik düzeltmesi gerçekleştirilmiş ve CFMASK algoritması ile hesaplanan bulut, gölge, su ve kar maskelerini içermektedir [36]. Landsat 8'den 2, 3, 4, 5, 6 ve 7 bantlar kullanılmıştır. Eskişehir iline ait olan görüntüler üzerinde çalışılmıştır(Şekil 2). Her mevsimden veriler üzerinde analiz gerçekleştirilmiştir. En iyi görüntü ve analizi yapabilmek için ilk olarak maske algoritması uygulanmıştır daha sonra medyan değerler hesaplanmıştır.
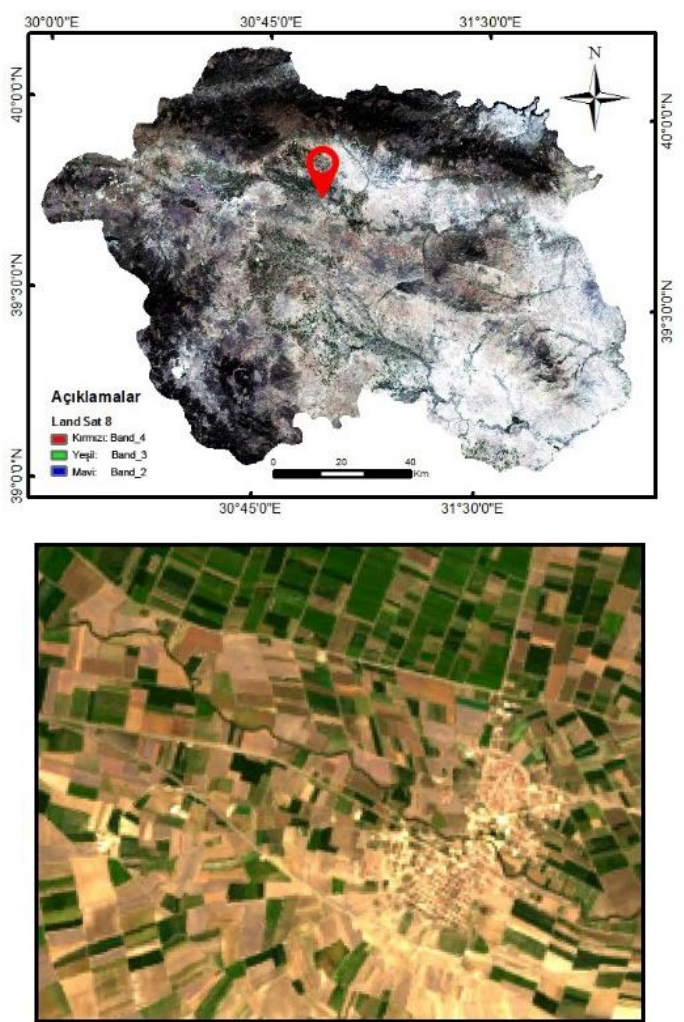

Şekil 2. Landsat 8 uydu görüntüsü

\subsection{Sentinel-1}

$\mathrm{Bu}$ araştırmada Sentinel-1 uydusunun VV ve VH bantları kullanılmıştır. Her bir mevsim için görüntü sayısı sırasıyla $87,90,88$ ve 93 'tür. Her bir mevsim için ayrı görüntüler ve görüntülerin medyanları kullanılarak hesaplanmıştır.
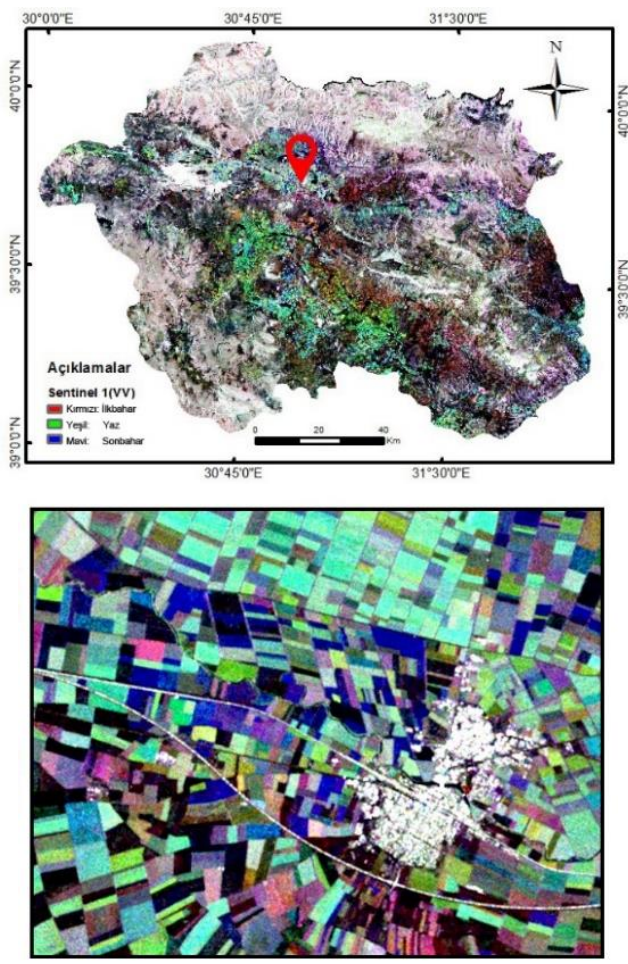

Şekil 3. Sentinel-1 VV uydu görüntüsü
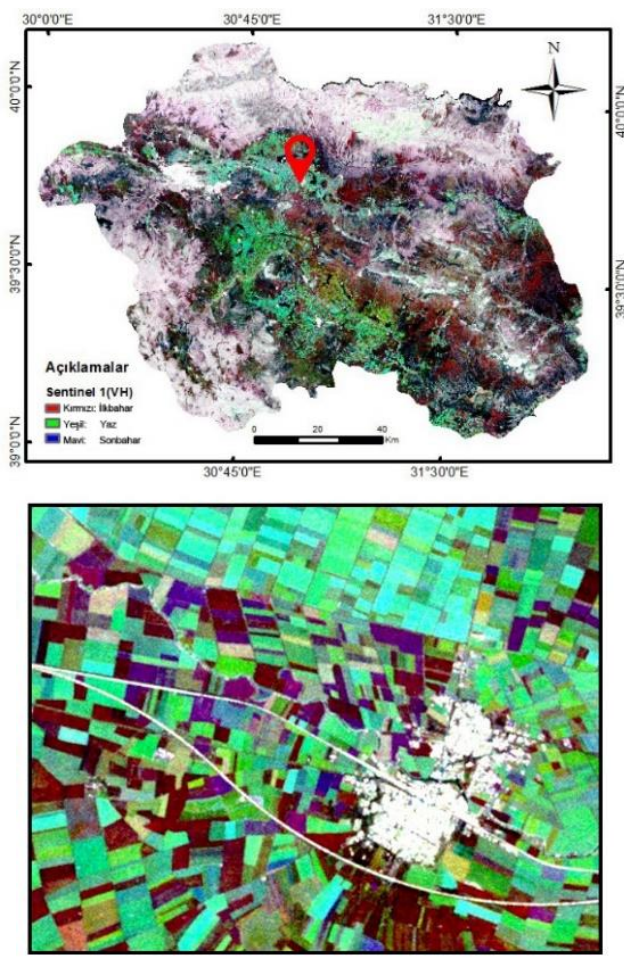

Şekil 4. Sentinel-1 VH uydu görüntüsü 
Her bir mevsim için RGB bantları Şekil 3 ve 4'de gösterilmiştir. Şekil 5'de renklerin ve mevsimlerin kombinasyonu görüntülenebilir. Bu kombinasyon tüm veri setlerinde kullanılmıştır.

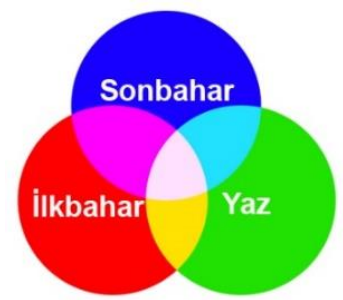

Şekil 5. Kırmızı, yeşil,mavi kombinlemesi [14]

Tablo 1. Sentinel-1 uydu bilgisi

\begin{tabular}{clcc}
\hline İsim & Tanımlama & Dalga boyu & Çözünürlük \\
\hline $\mathrm{HH}$ & $\begin{array}{l}\text { Single co-polarization, horizontal } \\
\text { transmit/horizontal receive }\end{array}$ & $5.405 \mathrm{GHz}$ & 10 metre \\
$\mathrm{HV}$ & $\begin{array}{l}\text { Dual-band cross-polarization, } \\
\text { horizontal transmit/vertical receive }\end{array}$ & $5.405 \mathrm{GHz}$ & 10 metre \\
$\mathrm{VV}$ & $\begin{array}{l}\text { Single co-polarization, vertical } \\
\text { transmit/vertical receive }\end{array}$ & $5.405 \mathrm{GHz}$ & 10 metre \\
$\mathrm{VH}$ & $\begin{array}{l}\text { Dual-band cross-polarization, } \\
\text { vertical transmit/horizontal receive }\end{array}$ & $5.405 \mathrm{GHz}$ & 10 metre \\
\hline
\end{tabular}

\subsection{Sentinel-2}

Sentilel-2 yüksek çözünürlüklü, geniş alanlı ve çok spektrumlu Copernicus arazi gözlem çalışmalarını destekleyen ve su, bitki örtüsü, toprak gibi alanların gözlemlenmesini sağlayan uydudur (Şekil 6).
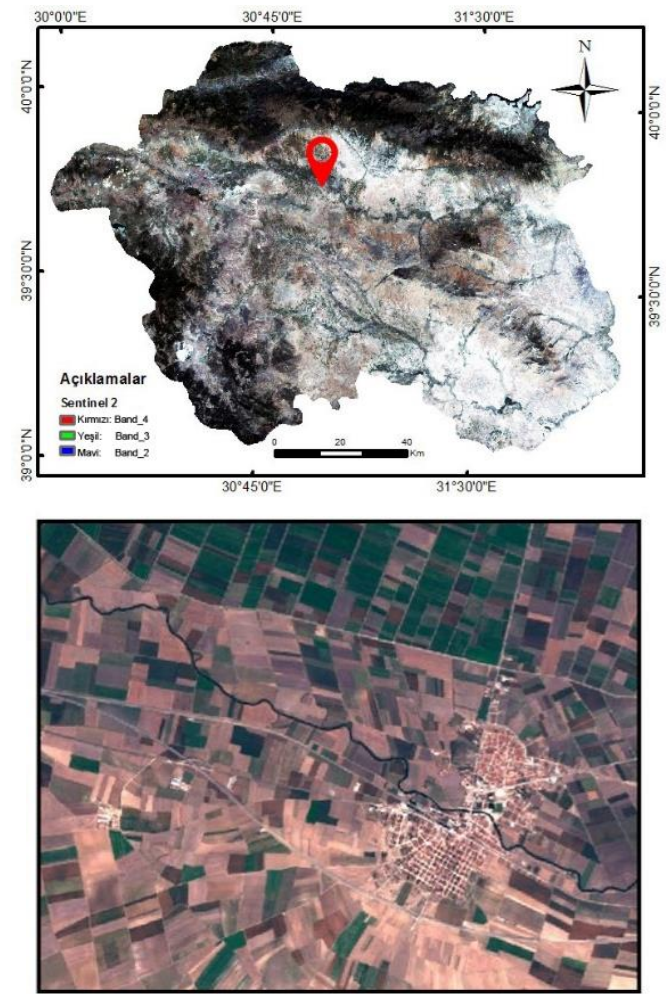

Şekil 6. Sentinel-2 uydu görüntüsü

\subsection{Indeksler}

NDVI, EVI, NDBI, NDWI ve Ui indeksleri Sentinel-2 uydusu kullanılarak hesaplanmıştır. Sadece NDVI indeksi hesaplanırken Landsat-8 uydusu görüntüsü kullanılmıştır. Her bir indeks için formüller Tablo 2'de gösterilmiştir. İndeks hesaplarını yapabilmek için ilk olarak ilgili tarih aralıklarına ait görüntüler belirlenmiştir. Daha sonra, her bir görüntü için indeks hesabı yapılmıştır. Son görüntü "maximum valve composite" algoritması kullanılarak piksel başına düşen maksimum değerler alınarak üretilmiştir.

Tablo 2. Araştırma kullanılan indeks bilgileri ve formülleri

\begin{tabular}{|c|c|c|}
\hline Tür & İndeks & Formül \\
\hline $\begin{array}{l}\text { Normalleştirilmiş } \\
\text { fark bitki örtüsü } \\
\text { endeksi[26] }\end{array}$ & NDVI & $\frac{N I R-R E D}{N I R+R E D}$ \\
\hline $\begin{array}{l}\text { Gelişmiş Bitki } \\
\text { Örtüsü } \\
\text { Endeksi[27] }\end{array}$ & EVI & $G * \frac{N I R-R E D}{N I R+\mathrm{C} 1 * R E D-C 2 * \text { Blue }+L}$ \\
\hline $\begin{array}{l}\text { Normalleştirilmiş } \\
\text { fark su } \\
\text { endeksi[28] }\end{array}$ & NDWI & $\frac{\text { Green }-N I R}{\text { Green }+N I R}$ \\
\hline $\begin{array}{l}\text { Normalleştirilmiş } \\
\text { fark oluşturma } \\
\text { indeksi[29] }\end{array}$ & NDBI & $\frac{S W I R 1-N I R}{S W I R 1+N I R}$ \\
\hline $\begin{array}{l}\text { Kentsel } \\
\text { İndeks[30] }\end{array}$ & UI & $\frac{S W I R 2-N I R}{S W I R 2+N I R}$ \\
\hline
\end{tabular}

Şekil 7'de Landsat-8 uydusu kullanılarak hesaplanan NDVI sonuçları görülmektedir ve Şekil 8'de ise Sentinel-2 uydusu kullanılarak hesaplanan NDVI sonuçları görülmektedir. Aşağıda bulunan görüntüde her bir mevsim için hesaplanan NDVI için RGB renk bantları kombinasyonlarından yararlanılmıştır.

Eğer tarım arazileri ile çalışma yapılacak ise, sarı ile işaretli alanlar ilkbahar aylarında maksimum NDVI değerine sahip olan alanlardır. Yeşil ile işaretli olanlar, yaz aylarında maksimum NDVI değerine sahiptir ve mavi ile işaretli alanlar ise, sonbahar aylarında maksimum değere sahip alanlardır. Beyaz işaretli olan alanlar ise, her bir sezona ait 3 ay içerisinde en yüksek değere sahip olan alanlardır. NDVI hesaplanması Landsat-8'e ait 103 görüntü kullanılarak hesaplanmıştır. Aynı indeks Sentinel-2'e ait 952 görüntü kullanılarak da hesaplanmıştır. 

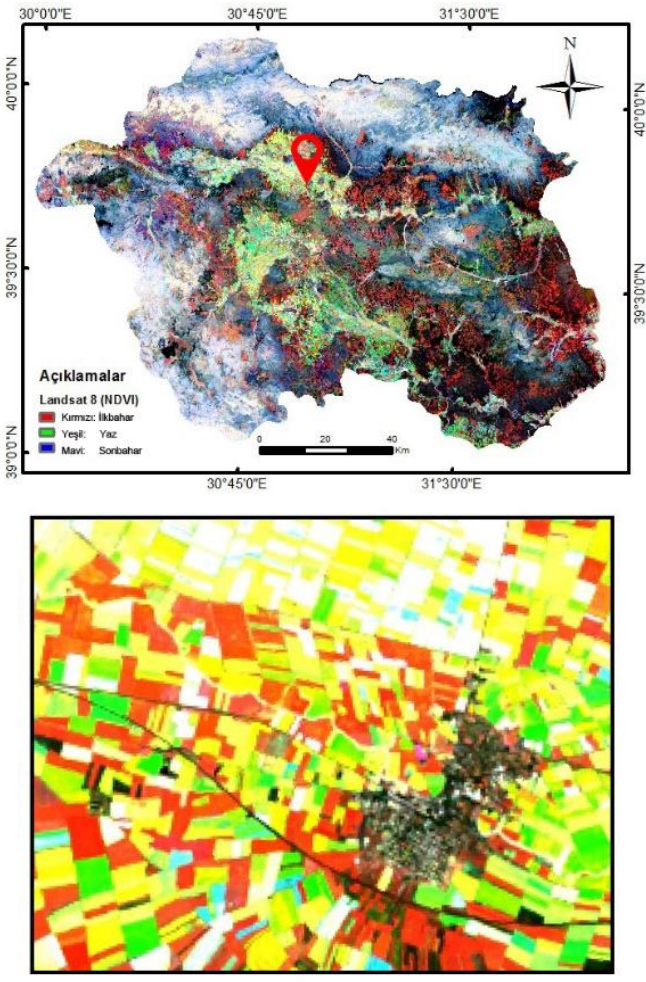

Şekil 7. NDVI - Landsat 8
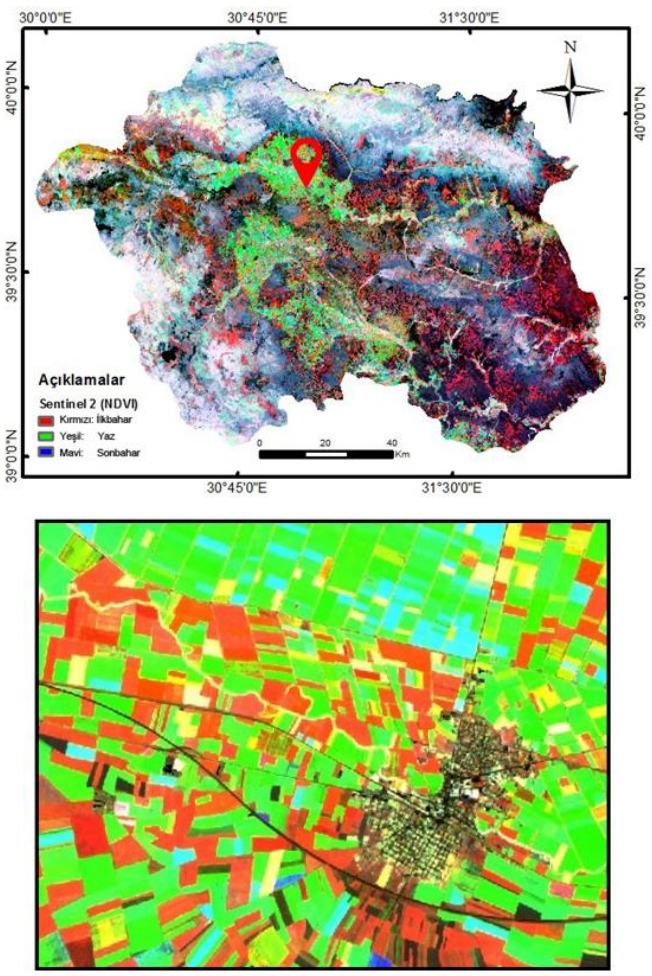

Şekil 8. NDVI - Sentinel-2

Aynı zamanda, her bir mevsim için EVI indekside hesaplanmıştır. Şekil 9'da EVI indeksin hesaplanması sonucunda ortaya çıkan sonuç görülmektedir. Her bir mevsime ait olan EVI indeks sonucunun daha iyi görünebilmesi için RGB bantlardan yararlanılmıştır.
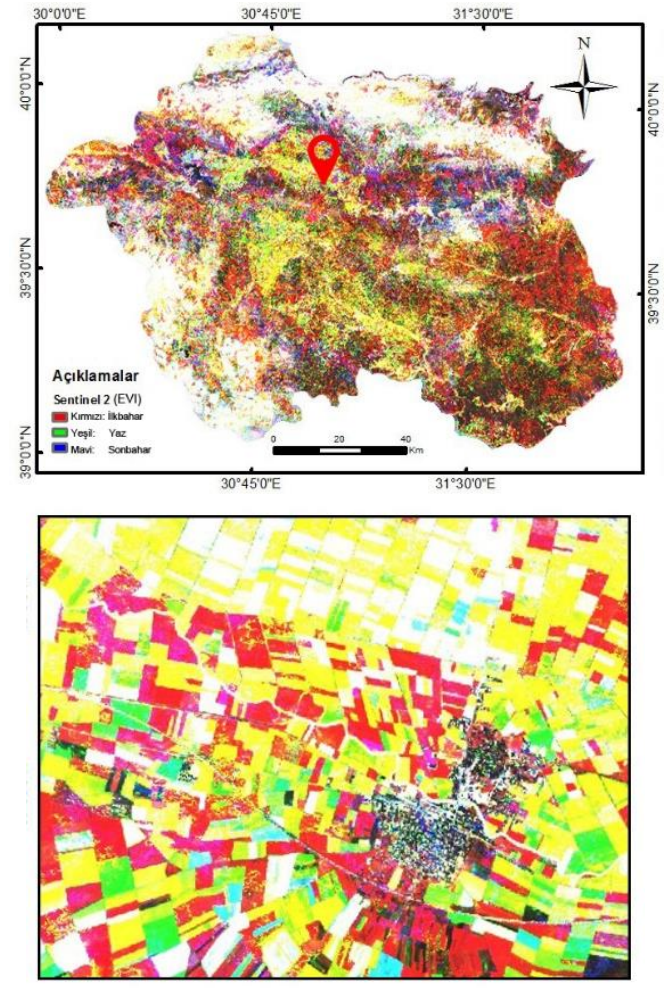

Şekil 9. EVI - Sentinel-2

NDBI, UI ve NDWI indeksleri Tablo 2'de verilen formüller ile hesaplanmıştır. Bu 3 indeks her bir mevsim için değil sadece yaz mevsim verileri kullanılarak hesaplanmıştır. Aşağıda bulunan Şekil 10, 11 ve 12 'de GEE üzerinde hesaplanan indekslerin sonuçları verilmiş̧ir.
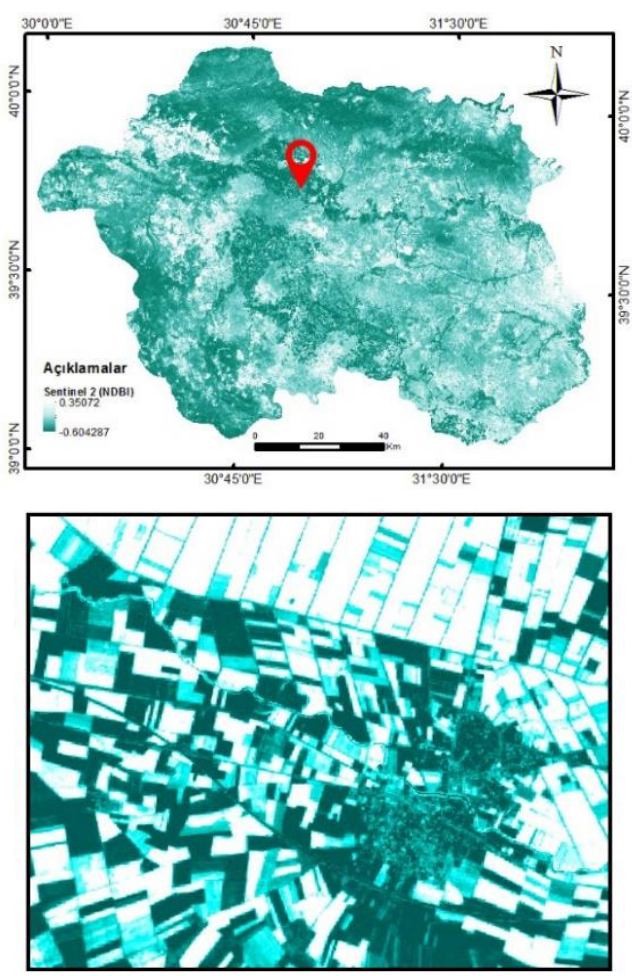

Şekil 10. NDBI - Sentinel-2 
Tablo 3. Araştırma kullanılan tüm verilerin detaylı bilgileri

\begin{tabular}{|c|c|c|c|}
\hline VERİ SETİ & Tarih Aralığ & $\begin{array}{c}\text { Görüntü } \\
\text { Sayıs1 }\end{array}$ & İşlem \\
\hline \multirow{4}{*}{$\begin{array}{l}\text { USGS Landsat } 8 \\
\text { Surface Reflectance } \\
\text { Tier } 1\end{array}$} & 2019-01-01 - 2019-04-01 & 27 & Median \\
\hline & 2019-04-01 - 2019-07-01 & 27 & Median \\
\hline & 2019-07-01 - 2019-10_01 & 29 & Median \\
\hline & 2019-10-01 - 2020-01-01 & 20 & Median \\
\hline \multirow{4}{*}{$\begin{array}{l}\text { Sentinel-2 MSI: } \\
\text { MultiSpectral } \\
\text { Instrument, Level-2A }\end{array}$} & 2019-01-01 - 2019-04-01 & 234 & Median \\
\hline & 2019-04-01 - 2019-07-01 & 234 & Median \\
\hline & 2019-07-01 - 2019-10-01 & 244 & Median \\
\hline & 2019-10-01 - 2020-01-01 & 240 & Median \\
\hline \multirow{4}{*}{$\begin{array}{l}\text { Sentinel-1 SAR } \\
\text { GRD: C-band } \\
\text { Synthetic Aperture } \\
\text { Radar Ground Range } \\
\text { Detected, log } \\
\text { scaling(VH) }\end{array}$} & 2019-01-01 - 2019-04-01 & 87 & Median \\
\hline & 2019-04-01 - 2019-07-01 & 90 & Median \\
\hline & 2019-07-01 - 2019-10-01 & 88 & Median \\
\hline & 2019-10-01 - 2020-01-01 & 93 & Median \\
\hline \multirow{4}{*}{$\begin{array}{l}\text { Sentinel-1 SAR } \\
\text { GRD: C-band } \\
\text { Synthetic Aperture } \\
\text { Radar Ground Range } \\
\text { Detected, log } \\
\text { scaling(VV) }\end{array}$} & 2019-01-01 - 2019-04-01 & 87 & Median \\
\hline & 2019-04-01 - 2019-07-01 & 90 & Median \\
\hline & 2019-07-01 - 2019-10-01 & 88 & Median \\
\hline & 2019-10-01 - 2020-01-01 & 93 & Median \\
\hline \multirow{4}{*}{$\begin{array}{l}\text { Sentinel-2 } \\
\text { EVI }\end{array}$} & 2019-01-01 - 2019-04-01 & 234 & $\operatorname{Max}$ \\
\hline & 2019-04-01 - 2019-07-01 & 234 & $\operatorname{Max}$ \\
\hline & 2019-07-01 - 2019-10-01 & 244 & $\operatorname{Max}$ \\
\hline & 2019-10-01 - 2020-01-01 & 240 & $\operatorname{Max}$ \\
\hline \multirow{4}{*}{$\begin{array}{l}\text { Sentinel-2 } \\
\text { NDVI }\end{array}$} & 2019-01-01 - 2019-04-01 & 234 & $\operatorname{Max}$ \\
\hline & 2019-04-01 - 2019-07-01 & 234 & $\operatorname{Max}$ \\
\hline & 2019-07-01 - 2019-10-01 & 244 & $\operatorname{Max}$ \\
\hline & 2019-10-01 - 2020-01-01 & 240 & $\operatorname{Max}$ \\
\hline \multirow{4}{*}{$\begin{array}{l}\text { Landsat } 8 \\
\text { NDVI }\end{array}$} & 2019-01-01 - 2019-04-01 & 27 & $\operatorname{Max}$ \\
\hline & 2019-04-01 - 2019-07-01 & 27 & $\operatorname{Max}$ \\
\hline & 2019-07-01 - 2019-10-01 & 29 & $\operatorname{Max}$ \\
\hline & 2019-10-01 - 2020-01-01 & 20 & $\operatorname{Max}$ \\
\hline Santinel-2 NDBI & 2019-04-01 - 2019-07-01 & 234 & $\operatorname{Max}$ \\
\hline Santinel-2 Ui & 2019-04-01 - 2019-07-01 & 234 & $\operatorname{Max}$ \\
\hline Santinel-2 NDWI & 2019-04-01 - 2019-07-01 & 234 & $\operatorname{Max}$ \\
\hline
\end{tabular}
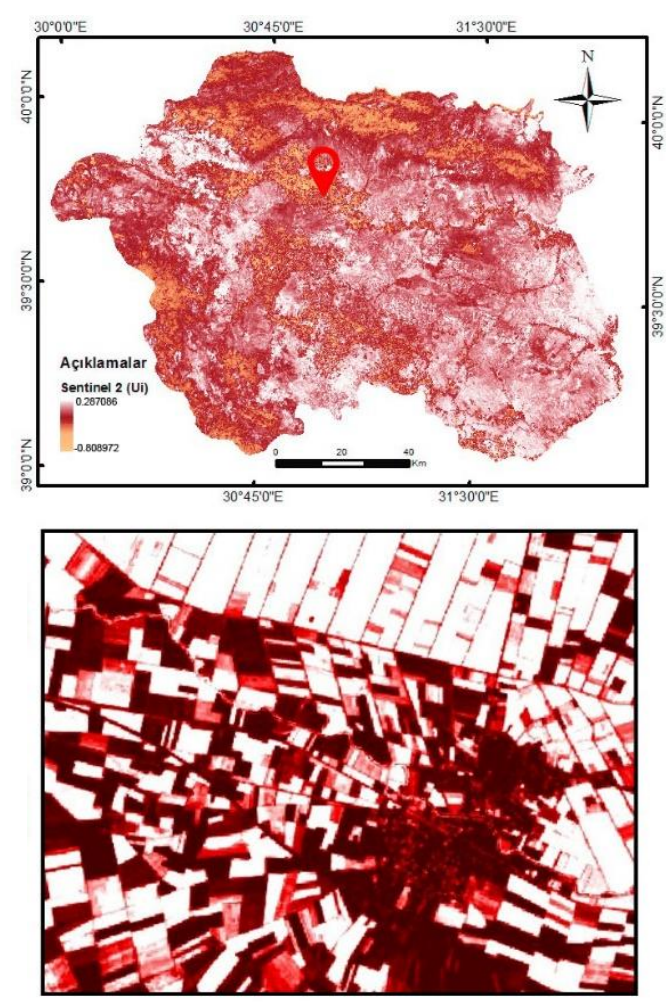

Şekil 11. UI - Sentinel-2
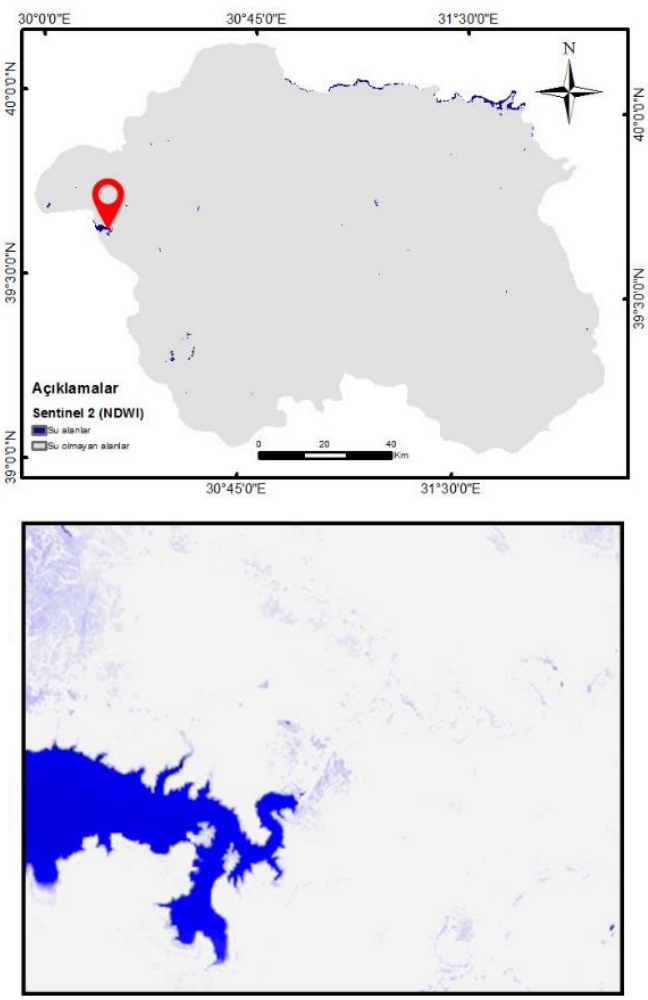

Şekil 12. NDWI - Sentinel-2 


\subsection{Siniflandırma metotlar}

GEE platformunda birçok farklı sınıflandırma yöntemi bulunmaktadır. Destek Vektör Makineleri (SVM) bunlardan bir tanesidir. SVM algoritması başarılı algoritmalardan birisi olarak bilinmektedir [37] ve son 10 yılda birçok çalışma SVM yöntemini parametrik olmayan kontrollü sınıflandırma çalışmalarında kullanmıştır [38-40]. Kisitlı veri olması durumunda SVM yöntemi, Maksimum Olabilirlik gibi diğer geleneksel yöntemlere nazaran çok daha iyi sonuç vermektedir [41, 42]. SVM sinıfları en iyi şekilde ayıran hiper düzlemleri kullanarak sınıflandırma işlemini yapmaktadır [43]. Bu araştırmada Destek Vektör Makineleri Kitaplığı (LibSVM) yöntemi kullanılmıştır [44].

Bu metotta ilk olarak farklı sınıflara ait eğitim noktaları seçilir. $\mathrm{Bu}$ çalışmada 5 farklı sınıflandırma alanı belirlenmiştir bunlar; Şehir alanı-yollar, su, ormanlıkkoruluk, tarım dışı araziler ve tarım arazileri olarak gösterilebilir. Aşağıda verilen Formül 1 ile örnek alanlarının sayısı belirlenmiştir. Bu formül her bir sınıf için 410 adet noktanın belirlenmesi ile uygulanmıştır. $\mathrm{Bu}$ noktaların seçimi Sentinel 2 ve Landsat 8'in görüntüleri incelenerek ve Google Earth Engine'in yüksek çözünürlüklü görüntüsü ile eşleştirilerek yapılmıştır. Daha sonra noktaların \%70'i eğitim için ve \%30'u ise test için rastgele seçilmiştir (Tablo 4).

$$
N=\frac{Z^{2}(p)(q)}{E^{2}}
$$

Yukarıdaki formülde $p$ tüm sınıflandırmanın beklenen doğruluğudur, $\mathrm{q}=100-p, E$ izin verilen hata sınırı ve $Z=2$ \%95 güven aralığında 1.96'nın standart sapmasıdır.
Tablo 4. Sınıflandırma bilgileri ve noktaların sayıları

\begin{tabular}{clcc}
\hline No. & \multicolumn{1}{c}{ Sınıf adı } & $\begin{array}{c}\text { Eğitim } \\
\text { Noktaları }\end{array}$ & $\begin{array}{c}\text { Test } \\
\text { Noktaları }\end{array}$ \\
\hline 1 & Şehir alanı-yollar & 287 & 123 \\
2 & Su & 287 & 123 \\
3 & Ormanlık-koruluk & 287 & 123 \\
4 & Tarım dışı araziler & 287 & 123 \\
5 & Tarım arazileri & 287 & 123 \\
\hline
\end{tabular}

Google Earth Engine ile verilerin filtrelenmesi; tarih aralığ1, coğrafi alan, bulut yüzdesi ve uydu görüntülerinde belirli özellikler seçilerek yapılır. $\mathrm{Bu}$ araştırmada, bu filtrelerden bazıları görüntü çağrılmasında kullanılmış ve özellikle indislerin hesaplanmasında Maximum Valio Composite algoritması kullanılmıştır.

\section{Bulgular ve tartışma}

Veri kombinasyonlarının ve katmanların seçimi aşama aşama yapılmıştır. İlk olarak, sınıflandırma işlemi yapılmıştır ve sonuçların iyileştirilmesi için diğer veriler eklenmiştir. İlk olarak Landsat 8, Sentinel 1 ve Sentinel 2 uydularının görüntüleri ayrı ayrı sınıflandırılmış, daha sonra, diğer araştırmacılar tarafından yapılan araştırmalara dayanarak başka katmanlar eklenmiştir. Testin en yüksek doğruluğunu elde etmeye çalışılması için literatürde olan kombinasyonlara ilave yeni kombinasyonlar eklenmiştir. Tablo 5'de sınıflandırma ve farklı bileşiklerin sonuçları görünebilmektedir. Aynı zamanda, her bir kombinasyon için genel doğruluk ve kappa katsayısı hesaplanmıştır.

Tablo 5. Farklı kombinasyonlar ve her bir kombinasyon için hesaplanan Genel doğruluk ve Kappa katsayısı bilgileri

\begin{tabular}{|c|c|c|c|c|}
\hline No. & Kombinasyon & Band & Genel doğruluk & Kappa katsayısı \\
\hline 1 & $\mathrm{~L} 8+\mathrm{S} 2+\mathrm{S} 1 \mathrm{VV}+\mathrm{L} 8 \mathrm{NDVI}+\mathrm{S} 2 \mathrm{NDVI}+\mathrm{S} 2 \mathrm{Ui}+\mathrm{S} 2 \mathrm{NDBI}+\mathrm{S} 2 \mathrm{NDWI}$ & 55 & 96.62 & 95.76 \\
\hline 2 & $\mathrm{~L} 8+\mathrm{S} 2+\mathrm{S} 1 \mathrm{VV}+\mathrm{S} 1 \mathrm{VH}$ & 48 & 94.44 & 93.03 \\
\hline 3 & $\mathrm{~L} 8+\mathrm{S} 2+\mathrm{S} 1 \mathrm{VH}$ & 44 & 94.41 & 93 \\
\hline 4 & $\mathrm{~L} 8+\mathrm{S} 2+\mathrm{S} 1 \mathrm{VV}+\mathrm{S} 1 \mathrm{VH}+\mathrm{L} 8 \mathrm{NDVI}+\mathrm{S} 2 \mathrm{NDVI}+\mathrm{S} 2 \mathrm{Ui}+\mathrm{S} 2 \mathrm{NDBI}+\mathrm{S} 2 \mathrm{NDWI}+\mathrm{S} 2 \mathrm{EVI}$ & 63 & 93.91 & 92.39 \\
\hline 5 & $\mathrm{~L} 8+\mathrm{S} 2+\mathrm{S} 1 \mathrm{VV}+\mathrm{S} 1 \mathrm{VH}+\mathrm{L} 8 \mathrm{NDVI}+\mathrm{S} 2 \mathrm{NDVI}+\mathrm{S} 2 \mathrm{Ui}+\mathrm{S} 2 \mathrm{NDBI}+\mathrm{S} 2 \mathrm{NDWI}$ & 59 & 93.75 & 92.18 \\
\hline 6 & $\mathrm{~L} 8+\mathrm{S} 2$ & 40 & 93.30 & 91.61 \\
\hline 7 & $\mathrm{~L} 8 \mathrm{NDVI}+\mathrm{S} 2 \mathrm{NDVI}+\mathrm{S} 1 \mathrm{VV}+\mathrm{S} 1 \mathrm{VH}+\mathrm{S} 2 \mathrm{Ui}+\mathrm{S} 2 \mathrm{NDBI}+\mathrm{S} 2 \mathrm{NDWI}$ & 59 & 93.24 & 91.55 \\
\hline 8 & $\mathrm{~L} 8+\mathrm{S} 1 \mathrm{VV}+\mathrm{S} 1 \mathrm{VH}$ & 32 & 92.91 & 91.13 \\
\hline 9 & $\mathrm{~L} 8+\mathrm{S} 2+\mathrm{S} 1 \mathrm{VV}$ & 44 & 92.09 & 90.12 \\
\hline 10 & $\mathrm{~S} 2+\mathrm{S} 1 \mathrm{VV}+\mathrm{S} 1 \mathrm{VH}+\mathrm{S} 2 \mathrm{NDVI}+\mathrm{S} 2 \mathrm{Ui}+\mathrm{S} 2 \mathrm{NDBI}+\mathrm{S} 2 \mathrm{NDWI}+\mathrm{S} 2 \mathrm{EVI}$ & 35 & 91.42 & 89.25 \\
\hline 11 & $\mathrm{~L} 8 \mathrm{NDVI}+\mathrm{S} 2 \mathrm{NDVI}+\mathrm{S} 1 \mathrm{VV}+\mathrm{S} 1 \mathrm{VH}+\mathrm{S} 2 \mathrm{Ui}+\mathrm{S} 2 \mathrm{NDBI}+\mathrm{S} 2 \mathrm{NDWI}+\mathrm{S} 2 \mathrm{EVI}$ & 63 & 90.61 & 88,25 \\
\hline 12 & $\mathrm{~S} 1 \mathrm{VV}+\mathrm{S} 1 \mathrm{VH}+\mathrm{S} 2 \mathrm{NDVI}$ & 12 & 91.27 & 89.07 \\
\hline 13 & $\mathrm{~L} 8+\mathrm{S} 1 \mathrm{VV}$ & 28 & 89.23 & 86.49 \\
\hline 14 & $\mathrm{~S} 2+\mathrm{S} 1 \mathrm{VV}+\mathrm{S} 1 \mathrm{VH}$ & 24 & 89.16 & 86.43 \\
\hline 15 & $\mathrm{~L} 8 \mathrm{NDVI}+\mathrm{S} 2 \mathrm{NDVI}+\mathrm{S} 1 \mathrm{VV}$ & 12 & 88.09 & 85.1 \\
\hline 16 & $\mathrm{~S} 2+\mathrm{S} 2 \mathrm{NDVI}$ & 20 & 87.46 & 84.34 \\
\hline 17 & $\mathrm{~S} 2$ & 16 & 85.35 & 81.66 \\
\hline 18 & $\mathrm{~S} 1 \mathrm{VV}+\mathrm{S} 1 \mathrm{VH}$ & 8 & 81.76 & 77.2 \\
\hline 19 & L8 & 24 & 75.88 & 69.88 \\
\hline
\end{tabular}

S1VV: Sentinel-1(VV); S1VH: Sentinel-1(VH); S2: Sentinel-2; L8: Landsat 8; L8NDVI: Landsat 8(NDVI); S2NDVI: Sentinel-2(NDVI); S2Ui: Sentinel-2(Ui); S2NDBI: Sentinel-2(NDBI); S2NDWI: Sentinel-2(NDWI); S2EVI: Sentinel-2(EVI) 

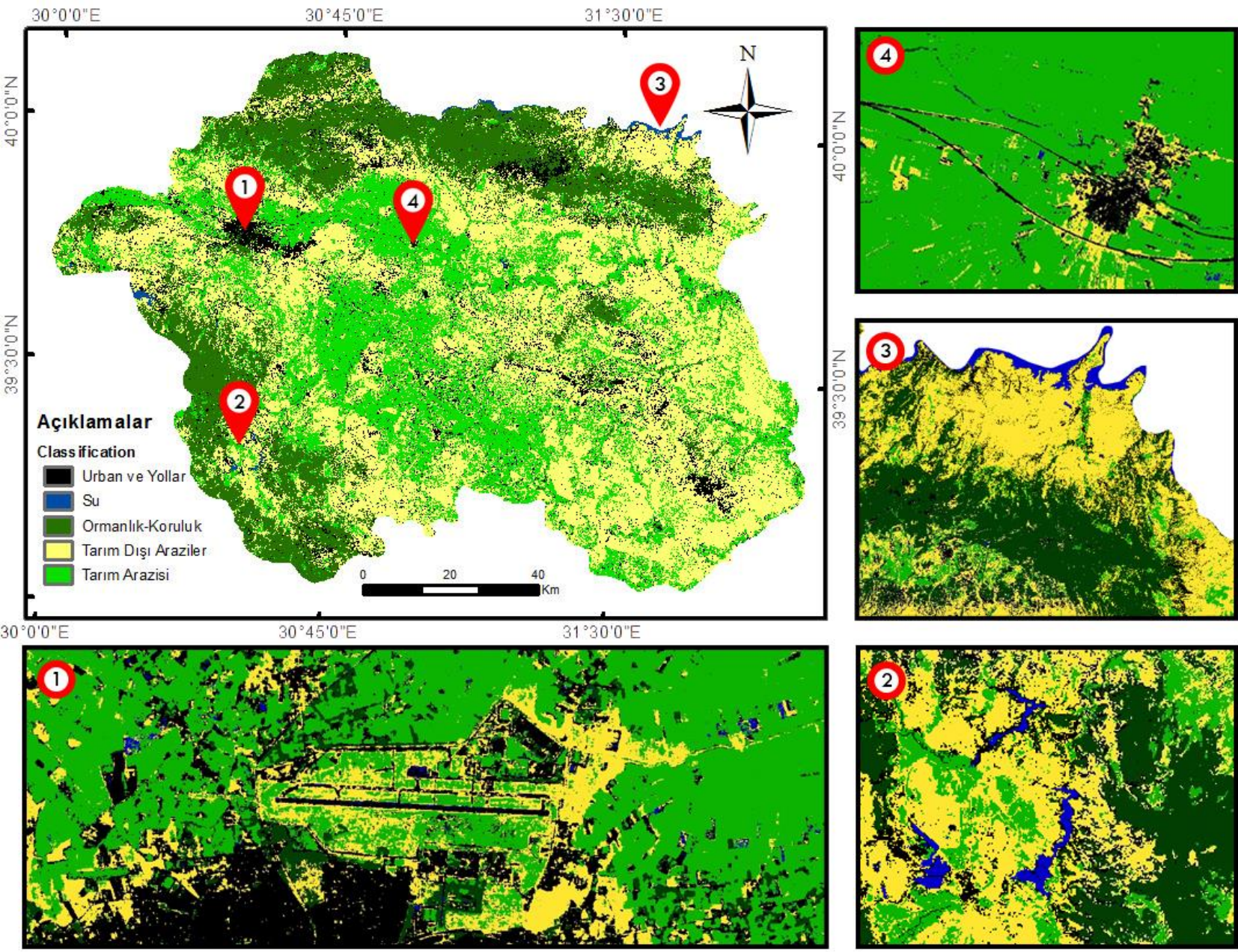

Şekil 13. L8 + S2 + S1VV + L8NDVI + S2NDVI + S2Ui + S2NDBI + S2NDWI sınıflandırma sonuçları

Tablo 5'de görüldüğü üzere, eğer sınıflandırma için sadece Landsat 8 uydu görüntüleri ve bantları kullanıldığında, genel doğruluk 75.88 ve Kappa değeri 69.88 olmaktadır. Eğer sınıflandırmada Sentinel-1 görüntüleri (VV ve VH bantları) kullanılırsa, genel doğruluğu ve Kappa sirasıly 81.76 ve 77.2 olarak bulunmaktadır. $\mathrm{Bu}$ sinıflandırmada sadece 8 bant kullanılmıştır. Bu bantlar, medyan algoritmasının kullanılması sonucu elde edilen 358 görüntünün VV ve VH bantlarıdır.

Sentinel-2 uydusu görüntülerinin kullanılmasında ise, genel doğruluk ve Kappa sirasiyla 85.35 ve 81.66'ya yükselmektedir. 16 adet katman sayısı ve sinıflandırma yapılmıştır. Medyan değeri 952 görüntü üzerinden elde edilmiştir.

Sonuçlar, bilgi katmanları eklenerek ve diğer uydu görüntüleri kullanarak, veriler birbirleriyle kombinlenerek ve farklı indeksler eklenerek, sınıflandırma doğruluğunun önemli ölçüde artırılabileceğini göstermektedir. Örneğin, Landsat ve Sentinel 2 uydu verileri birleştirilirse, genel doğruluk ve Kappa 93.30 ve 91.61 'e yükselmektedir. Ayrıca, Sentinel 1 uydusunun VV ve VH bantlarını eklenirse, toplam doğruluğun 94.44'e, Kappa'nın ise 93.03'e yükseldiği görülmektedir.

Endekslerin kullanımı sınıflandırma kalitesini artırmaktadır. Farklı indeksler hesaplayıp bunları bilgi katmanlarına ekleyerek sınıflandırma kalitesini artırmak da mümkündür. Sonuçlar göstermektedir ki; eğer 4 farklı indeksin hepsi hesaplanarak (NDVI, NDBI, Ui ve NDWI) ve Landsat 8 , Sentinel 2 ve Sentinel $1-\mathrm{VV}$ uydu verileri bir arada kullanıldığında doğruluk 96.62 ve kappa 95.76 olarak elde edilmektedir. Şekil 13'de sınıflandırma sonuçları verilmiş̧ir. Bu kombinasyonda, Landsat 8 ve Sentinel 2 uydu bantlarının her biri kullanılarak NDVI hesaplanmıştır. Fakat diğer indeks hesaplamalarında sadece Sentinel 2 uydu bantları kullanılmıştır. Sentinel uydu VH bandı bu veri kombinasyonunda kullanılmamışır çünkü bu bandın kullanılması genel doğruluğu ve Kappa'yı sırasıyla 93.75 ve 92.18'e düşürmüștür. Ayrıca, bantlar arasında EVI endeksi varsa, genel doğruluk ve Kappa 84 ve 80.07 'ye düşmektedir.

Landsat 8 ve Sentinel 2 uydu bantları kullanılmadan sadece Sentinel 1 uydu verileri ile NDVI, NDWI, NDBI ve Ui sınıflandırması yapıldığı zaman genel doğruluğun ve Kappa katsayısının sırasıyla 91.61 ve 88.25 'e yükseldiği görülmektedir.

\section{Sonuç ve öneriler}

$\mathrm{Bu}$ çalışma, Landsat 8, Sentinel-1 ve Sentinel-2 uydularından elde edilen verileri kullanarak Eskişehir ili arazi örtüsü haritasının üretiminde en iyi doğruluğu elde etmek amacıyla yapılmıştır. Bu amaçla, 01/01/2019 ve 
01/01/2020 döneminde bu üç uydudan çekilen tüm görüntüler işleme alınmıştır. Ayrıca, sınıflandırmada NDVI, EVI, NDWI, NDBI ve UI indeksleri hesaplanmıştır. Her sinıflandırma için Overal Accuracy ve Kappa Coefficient değerleri hesaplanmış ve sonuçlar karşılaştırılmıştır. Bu çalışma GEE platformunda yapılmıştır. GEE farklı kombinasyonları denemeyi sağlayan bununla birlikte sonuçları en kısa sürede ve en iyi şekilde almayı olanak sağlamaktadır. Sonuçlar, en iyi sınıflandırma sonucunun L8 $+\mathrm{S} 2+\mathrm{S} 1 \mathrm{VV}+\mathrm{L} 8 \mathrm{NDVI}+\mathrm{S} 2 \mathrm{NDVI}+\mathrm{S} 2 \mathrm{Ui}+\mathrm{S} 2 \mathrm{NDBI}+$ S2NDWI kombinasyonun elde edildiğini göstermektedir.

$\mathrm{Bu}$ kombinasyonun siniflandirılması ve hesaplanarak sonucu vermesi 60 dakikadan az sürede gerçekleştirmektedir. Eğer bu kombinasyon ve sınıflandırmayı sıradan bir bilgisayar üzerinde yazılım kullanarak yapılmaya çalışıldığında sonucu almak aylarca sürebilmektedir. Birçok bilgisayar bu analizleri yapabilmek için yeterli kapasiteye sahip değildir. GEE, araştırmacılara sayısız veri sunmaktadır. Aynı zamanda hazır kodların bulunduğu veya kendi kod bloklarını yazabilecekleri bir platform sunmaktadır. $\mathrm{Bu}$ çalışmanın farklı veriler ve sınıflandırma yöntemleri kullanarak diğer çalışmalara yol gösterici olması öngörülmektedir.

\section{Çıkar çatışması}

Yazarlar çıkar çatışması olmadığını beyan etmektedir.

\section{Benzerlik oranı (iThenticate): \%6}

\section{Kaynaklar}

[1] J. Liu, C. Zhang, L. Kou, and Q. Zhou, Effects of climate and land use changes on water resources in the Taoer river. Advances in Meteorology, 2017, Article ID 1031854, 13 pages 2017. https://doi.org/10.1155/ 2017/1031854

[2] G. Cai, H. Ren, L. Yang, N. Zhang, M. Du, and C. Wu, Detailed urban land use land cover classification at the metropolitan scale using a three-layer classification scheme. Sensors, 19(14), 3120, 2019. https://doi.org/ 10.3390/s19143120

[3] A. A. Vaighan, N. Talebbeydokhti, and A. M. Bavani, Assessing the impacts of climate and land use change on streamflow, water quality and suspended sediment in the Kor River Basin, Southwest of Iran. Environ Earth Sci, 76(15), 543, 2017. https://doi.org/10.1007 /s12665-017-6880-6

[4] L. Li, Y. Chen, X. Yu, R. Liu, and C. Huang, Sub-pixel flood inundation mapping from multispectral remotely sensed images based on discrete particle swarm optimization. ISPRS J. Photogramm. Remote Sens., 101, 10-21, 2015. https://doi.org/10.1016/j.isprsjprs. 2014.11.006

[5] X. Zhang, L. Han, L. Han, and L. Zhu, How well do deep learning-based methods for land cover classification and object detection perform on high resolution remote sensing imagery?. Remote Sens., 12(3), 417, 2020. https://doi.org/10.3390/rs12030417

[6] C. Zhang, P. A. Harrison, X. Pan, H. Li, I. Sargent, and P. M. Atkinson, Scale Sequence Joint Deep Learning (SS-JDL) for land use and land cover classification.
Remote Sens. Environ., 237:111593, 2020. https://doi.org/10.1016/j.rse.2019.111593

[7] C. Zhang, S. Wei, S. Ji, and M. Lu, Detecting largescale urban land cover changes from very high resolution remote sensing images using cnn-based classification. ISPRS Int J Geo-Information, 8(4), 189, 2019. https://doi.org/10.3390/ijgi8040189

[8] K. Hussein, K. Alkaabi, D. Ghebreyesus, M. U. Liaqat, and H. O. Sharif, Land use/land cover change along the Eastern Coast of the UAE and its impact on flooding risk. Geomatics, Nat Hazards Risk, 11(1), 112-30, 2020. https://doi.org/10.1080/19475705.2019.1707718

[9] E. F. Lambin, H. J. Geist, and E. Lepers, Dynamics of land-use and land-cover change in tropical regions. Annu. Rev. Environ. Resour., 28(1), 205-41, 2003. https://doi.org/10.1146/annurev.energy.28.050302.105 459

[10] Essential Climate Variables, World Meteorological Organization (WMO). https://public.wmo.int/en/ programmes/global-climate-observing-

system/essential-climate-variables Accessed: Jan. 05, 2021.

[11] N. Pettorelli et al., Framing the concept of satellite remote sensing essential biodiversity variables: challenges and future directions. Remote Sens. Ecol. Conserv., 2(3), 122-31, 2016. https://doi.org/10.1002/ rse2.15

[12] E. F. Lambin and H. J. Geist, Land-Use and LandCover Change: Local Processes and Global Impacts. Springer Science \& Business Media, 2008.

[13] L. Carrasco, A. W. O’Neil, R. D. Morton, and C. S. Rowland, Evaluating combinations of temporally aggregated Sentinel-1, Sentinel-2 and Landsat 8 for land cover mapping with Google Earth Engine. Remote Sens., 11(3), 288, 2019. https://doi.org/10.3390 /rs11030288

[14] J. R. Jensen, Introductory Digital Image Processing: A Remote Sensing Perspective. Prentice-Hall Inc., 1996.

[15] The Copernicus Open Access Hub, European Space Agency. https://scihub.copernicus.eu/ Accessed: Jan. 05, 2021

[16] Sentinel-1, European Space Agency. https://sentinel. esa.int/web/sentinel/missions/sentinel-1 Accessed: Jan. 05, 2021.

[17] Sentinel-2, European Space Agency. https://sentinel .esa.int/web/sentinel/missions/sentinel-2 Accessed: Jan. 05, 2021.

[18] Landsat 8, U.S. Geological Survey. https://www. usgs.gov/land-resources/nli/landsat/landsat-8 Accessed: Jan. 05, 2021.

[19] N. Gorelick, M. Hancher, M. Dixon, S. Ilyushchenko, D. Thau, and R. Moore, Google Earth Engine: Planetary-scale geospatial analysis for everyone. Remote Sens. Environ., 202, 18-27, 2017. https://doi.org/10.1016/j.rse.2017.06.031

[20] X. Wang et al., Tracking annual changes of coastal tidal flats in China during 1986-2016 through analyses of Landsat images with Google Earth Engine. Remote 
Sens. Environ., 238, 110987, 2020. https://doi.org/ 10.1016/j.rse.2018.11.030

[21] N. You and J. Dong, Examining earliest identifiable timing of crops using all available Sentinel 1/2 imagery and Google Earth Engine. ISPRS J. Photogramm. Remote Sens., 161, 109-23, 2020. https://doi.org/ 10.1016/j.isprsjprs.2020.01.001

[22] G. Mateo-García, L. Gómez-Chova, J. Amorós-López, J. Muñoz-Marí, and G. Camps-Valls, Multitemporal cloud masking in the Google Earth Engine. Remote Sens., 10(7), 1079, 2018. https://doi.org/10.3390/ rs 10071079

[23] Q. Weng, Z. Mao, J. Lin, and W. Guo, Land-use classification via extreme learning classifier based on deep convolutional features. IEEE Geosci Remote Sens Lett, 14(5), 704-8, 2017. https://doi.org/10.1109 /LGRS.2017.2672643

[24] K. Islam, M. Jashimuddin, B. Nath, and T. K. Nath, Land use classification and change detection by using multi-temporal remotely sensed imagery: The case of Chunati wildlife sanctuary, Bangladesh. Egypt J Remote Sens Sp Sci, 21(1), 37-47, 2018. https://doi.org/10.1016/j.ejrs.2016.12.005

[25] J. R. B. Fisher, E. A. Acosta, P. J. Dennedy-Frank, T. Kroeger, and T. M. Boucher, Impact of satellite imagery spatial resolution on land use classification accuracy and modeled water quality. Remote Sens Ecol Conserv, 4(2), 137-49, 2018. https://doi.org/ $10.1002 /$ rse 2.61

[26] T. Hu, J. Yang, X. Li, and P. Gong, Mapping urban land use by using landsat images and open social data. Remote Sens., 8(2), 151, 2016. https://doi.org/ $10.3390 / \mathrm{rs} 8020151$

[27] B. Matsushita, W. Yang, J. Chen, Y. Onda, and G. Qiu, Sensitivity of the enhanced vegetation index (EVI) and normalized difference vegetation index (NDVI) to topographic effects: A case study in high-density cypress forest. Sensors, 7(11), 2636-51, 2007. https://doi.org/10.3390/s7112636

[28] W. Li et al., A comparison of land surface water mapping using the normalized difference water index from TM, ETM+ and ALI. Remote Sens., 5(11), 5530 49, 2013. https://doi.org/10.3390/rs5115530

[29] T. L. Dammalage and N. T. Jayasinghe, Land-use change and its impact on urban flooding: A case study on Colombo district flood on May 2016. Eng. Technol. Appl. Sci. Res., 9(2), 3887-91, 2019. https://doi.org/ 10.48084/etasr. 2578

[30] H. Li et al., Mapping urban bare land automatically from Landsat imagery with a simple index. Remote Sens., 9(3), 249, 2017. https://doi.org/10.3390/ rs9030249

[31] S. Ergen, A. Çelik, N. Çalişkan ve V. Yıldırım, Eskişehir istatistikleri. Eskişehir Büyükşehir Belediyesi Yayını, Eskişehir, 2018. http://www. eskisehir.bel.tr/dosyalar/istatisliklerle_eskisehir/2018. pdf

[32] J. Koskinen et al., Participatory mapping of forest plantations with Open Foris and Google Earth Engine.
ISPRS J. Photogramm. Remote Sens., 148, 63-74, 2019. https://doi.org/10.1016/j.isprsjprs.2018.12.011

[33] Y. Wang, J. Ma, X. Xiao, X. Wang, S. Dai, and B. Zhao, Long-term dynamic of Poyang Lake surface water: A mapping work based on the Google Earth Engine cloud platform. Remote Sens., 11(3), 313, 2019. https://doi.org/10.3390/rs11030313

[34] M. Venkatappa, N. Sasaki, R. P. Shrestha, N. K. Tripathi, and H.-O. Ma, Determination of vegetation thresholds for assessing land use and land use changes in Cambodia using the Google Earth Engine cloudcomputing platform. Remote Sens., 11(13), 1514, 2019. https://doi.org/10.3390/rs11131514

[35] P. R. Mirelva and R. Nagasawa, Application of Sentinel-1 data for classifying croplands using Google Earth Engine. Int. J. Geoinformatics, 15(3), 2019.

[36] Earth Engine Data Catalog. Google. https://developers. google.com/earth-engine/datasets Accessed: January 2021.

[37] D. Poursanidis, N. Chrysoulakis, and Z. Mitraka, Landsat 8 vs. Landsat 5: A comparison based on urban and peri-urban land cover mapping. Int. J. Appl. Earth Obs. Geoinf., 35, 259-69, 2015. https://doi.org/ 10.1016/j.jag.2014.09.010

[38] G. M. Foody and A. Mathur, Toward intelligent training of supervised image classifications: directing training data acquisition for SVM classification. Remote Sens. Environ., 93(1-2), 107-17, 2004. https://doi.org/10.1016/j.rse.2004.06.017

[39] M. Pal and P. M. Mather, Support vector machines for classification in remote sensing. Int. J. Remote Sens., 26(5), 1007-11, 2005. https://doi.org/10.1080/ 01431160512331314083

[40] W. Li, R. Dong, H. Fu, J. Wang, L. Yu, and P. Gong, Integrating Google Earth imagery with Landsat data to improve 30-m resolution land cover mapping. Remote Sens. Environ., 237, 111563, 2020. https://doi.org/ 10.1016/j.rse.2019.111563

[41] P. Mantero, G. Moser, and S. B. Serpico, Partially supervised classification of remote sensing images through SVM-based probability density estimation. IEEE Trans. Geosci. Remote Sens., 43(3), 559-70, 2005. https://doi.org/10.1109/TGRS.2004.842022

[42] G. Mountrakis, J. Im, and C. Ogole, Support vector machines in remote sensing: A review. ISPRS J. Photogramm. Remote Sens., 66(3), 247-59, 2011. https://doi.org/10.1016/j.isprsjprs.2010.11.001

[43] S. Park, J. Im, S. Park, C. Yoo, H. Han, and J. Rhee, Classification and mapping of paddy rice by combining Landsat and SAR time series data. Remote Sens., 10(3), 447, 2018. https://doi.org/10.3390/rs10030447

[44] C.-C. Chang, LIBSVM: a library for support vector machines. ACM Transactions on Intelligent Systems and Technology, 2, 3, article:27: 1--27, 2011. https://doi.org/10.1145/1961189.1961199

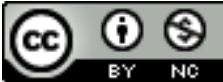

